\title{
Study of Tm-doped Aluminosilicate films for Integration of Lasers on a SOI Silicon Photonics Platform
}

\author{
Colin J. Mitchell, Amy S.K. Tong, James S. Wilkinson, Jacob I. Mackenzie \\ Optoelectronics Research Centre, University of Southampton, Southampton SO17 1BJ, UK
}

Thulium-doped glass has recently been highlighted as a potential candidate for amplifiers in a new telecommunications window, due to its potential for strong gain across a broad bandwidth in the 2-micron regime [1]. However, the use of such technology in a silicon or planar platform has received much less attention [2,3]. Lack of on-chip lasers is an obstacle to progress in silicon photonics with much research focused on mounting processed III-V lasers, bonding gain material, or the deposition of gain material onto SOI wafers.

Here we report the preparation and study of Tm-doped aluminosilicate glass, which has been demonstrated as an efficient laser/amplifier in fibre-technology covering a 1.7-2.1 $\mu \mathrm{m}$ window. To achieve efficient operation the $\mathrm{Tm}^{3+}$ doping concentration is typically optimised for enhancing cross relaxation energy exchange between the ${ }^{3} \mathrm{H}_{4}$ and ${ }^{3} \mathrm{~F}_{4}$ energy levels allowing an efficient "two-for-one" pumping approach [4]. Fluorescent emission and gain can then be achieved by pumping with readily available $\sim 795 \mathrm{~nm}$ sources diode-lasers. As such we have started preliminary investigations of higher concentrations to attempt to obtain enhanced gain per unit length devices.

Waveguide films were fabricated by sputtering in an $\mathrm{Ar}-\mathrm{O}_{2}$ atmosphere from powder-pressed aluminosilicate targets with three different compositions of $\mathrm{Tm}_{2} \mathrm{O}_{3}\left(3,7,10 \mathrm{wt} \% \mathrm{Tm}_{2} \mathrm{O}_{3}\right)$, and with a 1:10 ratio of Tm to $\mathrm{Al}$ atoms. This level of $\mathrm{Al}$ composition was observed to reduce clustering of the $\mathrm{Tm}^{3+}$ in $\mathrm{Tm}$-doped fibres [4]. The films were deposited on silicon substrates with thermal silica grown as a lower cladding. After deposition samples were cleaved into segments and annealed at different temperatures. The films were characterised for thickness, surface roughness, refractive index, fluorescence emission spectra (Fig.1a) and excited-state lifetime (Fig.1b) when pumped at $792 \mathrm{~nm}$. Fluorescence was collected via a $1.5 \mathrm{~mm}$ diameter fibre, filtering out the pump signal with an RG1000 long-pass filter. Channel waveguides were fabricated by ion beam milling to allow measurement of the absorption cross section at the pump wavelength $(792 \mathrm{~nm})$, achieving a value of $\sim 5 \times 10^{-21} \mathrm{~cm}^{2}$.
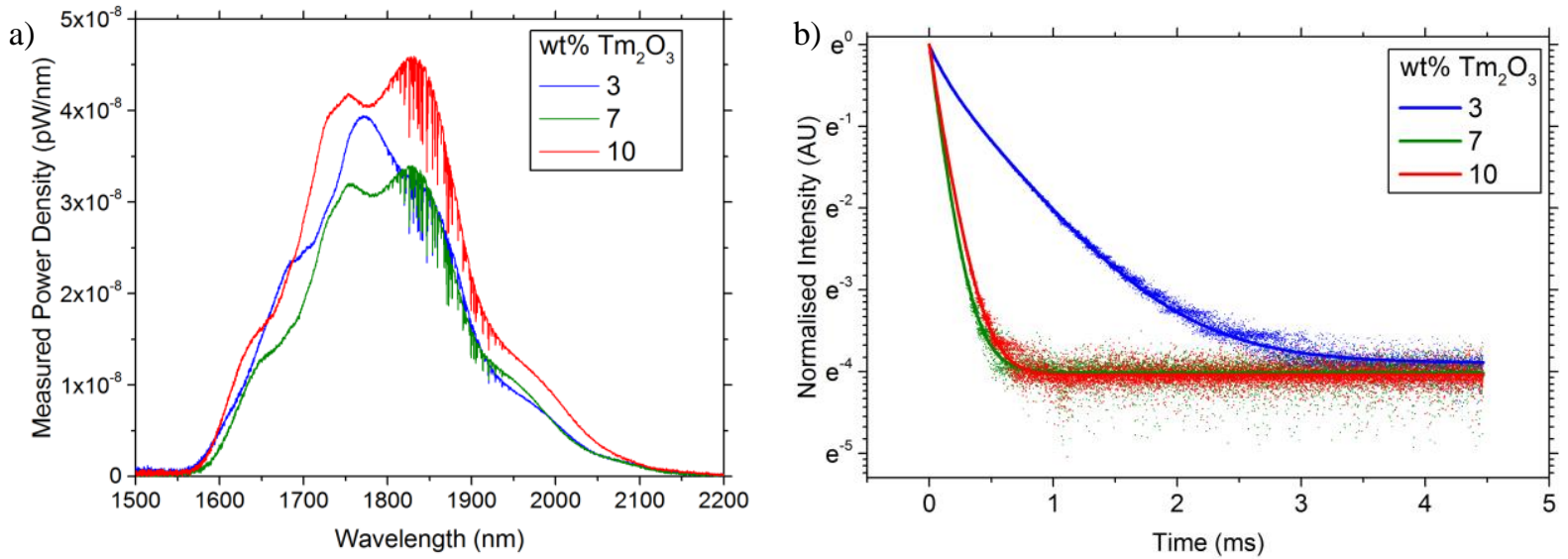

Fig. 1 a) Fluorescence spectra for varying Tm compositions, and, b) corresponding lifetime measurements

The longest lifetime was observed for the $3 \mathrm{wt} \% \mathrm{Tm}_{2} \mathrm{O}_{3}$ film, which had an intermediate fluorescence intensity compared to the other compositions. The longer lifetime compares favourably with published work [4] indicating that the $\mathrm{Tm}^{3+}$ ions are activated correctly in the ligand. A reduction in lifetime with increased composition is potentially a result of ion-ion interaction and will be the focus of future investigations. However, the $10 \mathrm{wt} \%$ $\mathrm{Tm}_{2} \mathrm{O}_{3}$ films provide the highest intensity indicating that there is scope for higher gains with an optimised $\mathrm{Al}$ composition. Varying annealing conditions and composition has shown longer lifetimes can be reached at these higher concentrations. These results, and others to be presented, demonstrate the potential for the development of a $2 \mu \mathrm{m}$ SOI integrated laser based on further developments of the Tm-doped aluminosilicate system.

\section{References}

[1] Z. Li, A. M. Heidt, J. M. O. Daniel, Y. Jung, S. U. Alam, and D. J. Richardson, "Thulium-doped fiber amplifier for optical communications at $2 \mu \mathrm{m}$ " Opt. Express 17(8), 9289 (2013).

[2] N. Li, P. Purnawirman, Z. Su, E. S. Magden, P. T. Callahan, K. Shtyrkova, M. Xin, A. Ruocco, C. Baiocco, E. P. Ippen, F. X. Kärtner J. D. B. Bradley, D. Vermeulen and M. R. Watts, "High-power thulium lasers on a silicon photonics platform" Opt. Lett. 42, 1181 (2017). [3] P. Loiko, and M. Pollnau, "Stochastic Model of Energy-Transfer Processes Among Rare-Earth Ions. Example of $\mathrm{Al}_{2} \mathrm{O}_{3}: \mathrm{Tm}^{3+"} \mathrm{Opt}^{3} \mathrm{Lett}$ 42, 1181 (2017).

[4] S. D. Jackson and S. Mossman, "Efficiency dependence on the $\mathrm{Tm}^{3+}$ and $\mathrm{Al}^{3+}$ concentrations for Tm${ }^{3+}$-doped silica double-clad fiber lasers" Appl. Opt, 42, 15, 2702 (2003) 